\title{
O BRINCAR COMO CONSTRUÇÃO RACIONAL NAS AULAS DE EDUCAÇÃ̃O FÍSICA
}

\author{
Andrize Ramires Costa' \\ Thais Emanuelle da Silva Barros² \\ Elenor Kunz $z^{3}$
}

\section{RESUMO}

O foco principal deste ensaio é a criança, que sente um enorme prazer em "Se-Movimentar". A base desse movimento reside na necessidade natural que ela tem para brincar. Ocorre que a sua tendência natural de "Se-Movimentar" e brincar rapidamente se transforma em atividade social e cultural pela própria apropriação de elementos da cultura e pela indução do meio onde nasce, ocasionada, em parte, pela imposição dos adultos a atividades aceitas e reconhecidas por eles. Finalizamos com a Educação Física, que geralmente não permite às crianças experiências próprias de movimento, brincadeiras e jogos, em favor de um movimento "correto", pré-constituído, ou seja, criado por terceiros, para atender a compromissos futuros de desenvolvimento, permitindo, muitas vezes, uma das experiências mais alienantes e castradoras da liberdade e criatividade humana.

Palavras-chave: "Se-movimentar". Crianças. Brincar. Movimento humano

1 Doutora em Teoria e Prática Pedagógica. Professora da Faculdade de Educação Física do Instituto Cearense de Educação da Universidade Federal do Pará (FEF/ICEA/UFPA). Belém/Pará, Brasil. E-mail: andrize.costa@gmail.com

2 Mestre em Educação Física. Docente da Secretaria de Educação do Estado de Santa Catarina (SED/SC). Florianópolis/Santa Catarina, Brasil. E-mail: thais_emanuellibarros@hotmail.com

3 Doutor em Educação Física. Professor da Universidade Federal de Santa Catarina (UFSC). Florianópolis/Santa Catarina, Brasil. E-mail: elenkunz@terra.com.br 


\title{
CONSTRUCTION HOW TO PLAY RATIONAL IN PHYSICAL EDUCATION CLASSES
}

\begin{abstract}
In this essay we bring main focus is the child who always has great pleasure in "Selfmovement". The basis for his "Self- movement" is the natural need of the child to play. It turns out that the natural tendency of "If jogging " and play the child quickly turns into social and cultural activity by the appropriation of elements of the culture and environment that arise by induction, for the most part, by the imposition of adults accepted activities and recognized by them, finalized pointing Physical Education which often do not allow their own experiences children movement, play and for games of a movement "right " pregiven and created by third parties, to meet future development undertakings by often one of the most alienating and castrating experiences of freedom and human creativity.
\end{abstract}

Keywords: "Moving one self". Children. Play. Human movement

\section{EL JUGAR COMO CONSTRUCIÓN RACIONAL EN LAS CLASES DE EDUCACIÓN FÍSICA}

RESUMEN

El objetivo principal de este ensayo es el niño que siente un placer enorme en "Movimentarse". La base de este movimiento radica en la necesidad natural que tiene para jugar. Sucede que su tendencia natural de "Movimentarse" y jugar se convierte rápidamente en actividad social y cultural por la apropiación de elementos culturales y por la inducción del medio donde nació, causada en parte por la imposición de los adultos a actividades aceptadas y reconocidas por ellos. Se concluye con la Educación Física, que por lo general no permite a los niños experiencias propias de movimiento y juegos a favor de un movimiento "derecho", pre-constituido, creado por otros para responder a los compromisos de desarrollo futuro, permitiendo, a menudo, una de las experiencias más alienantes y castradoras de la libertad y la creatividad humana.

Palabras clave: "Movimentarse". Niños. Jugar. Movimiento humano 


\section{INTRODUÇÃO}

O ensino formal como um todo tem assumido, em grande parte, a função institucional de formar e educar, oferecendo os espaços necessários ao desenvolvimento e à integração social, servindo a um processo de socialização da criança e do jovem. Porém, tem se constituído, ao mesmo tempo, em uma imposição social. À medida que exerce uma influência intencional sobre os alunos, o ensino pode ser considerado um importante modo de manipulação (KUNZ, 2015).

Segundo Kunz, a tarefa da escola de introduzir as crianças no mundo social organizado não pode ser realizada a partir de uma cópia fiel da realidade, sem que antes seus procedimentos e consequências sejam questionados e para que todos possam entender a abrangência ou o poder dessa manipulação. É justamente pelo fato de caber aos professores a tarefa de estruturar a realidade, priorizando um fenômeno ao invés de outro, agrupando, estabelecendo relações, suprimindo, selecionando o que é mais importante, que acaba prevalecendo a sua visão de mundo, e logo, o modo pelo qual a realidade se torna acessível e manipulável.

Uma reflexão pedagógica sobre essa situação deve tocar, de forma mais intensa, o professor, à medida que o ensino influencia a visão de mundo do aluno. E ao lado do "o que" e do "como" deve ocorrer essa influência, é necessário entender, principalmente, "o porquê" disso tudo. Ou seja, por que ensinamos, por que ministramos aulas? Como entender a questão de que o ensino deve se ocupar da transmissão de conhecimentos e habilidades exigidos pelos diferentes contextos sociais? Se assim for, deve-se entender o ensino enquanto uma atividade técnica sem nenhum compromisso com valores.

De forma implícita ou explícita, a verdade dos conteúdos e métodos de ensino está sempre vinculada a determinados valores e normas, cabendo ao profissional de Educação Física refletir sobre essa situação e considerar, inclusive, a situação dos alunos e sua contribuição no desenvolvimento desse processo, buscando estabelecer uma responsabilidade individual e autodeterminada (LANGENFELD apud KUNZ, 2015).

Mesmo que o desenvolvimento e a capacitação, assim como a educação e a socialização, sejam relações dialéticas, é possível verificar certo deslocamento de questões centrais quando se trata do desenvolvimento de personalidades e das capacidades de um agir na sociedade. No contexto atual, a escola parece contribuir antes para a formação de pessoas produtivas, orientada ao rendimento, do que criar uma cultura escolar centrada na pessoa (IJSENDOORN apud HEIJ, 2005).

Desta forma, é fundamental caracterizar o ser humano como um "Homo se movens", conforme afirma Gordijn (1980 apud HEIJ, 2009, p. 45), isto é, um ser que precisa se movimentar. Por isso, a Educação Física não pode partir de exercícios físicos feitos sob um comando, mas do próprio movimentar-se humano, e também não pode almejar apenas rendimentos físicos, e sim, a autonomia criativa e autorregulativa do ser humano. Eis, portanto, onde reside a base educacional da Educação Física.

Assim sendo, o objetivo deste ensaio é, inicialmente, constatar e denunciar o excesso de atividades na agenda diária das crianças em que o ato de "Brincar e Se-movimentar" 
tem se tornado cada vez mais ausente, e depois, anunciar, de forma fundamentada, a imprescindível necessidade humana por essas atividades, inerentes ao ser criança.

\section{Movimento enquanto um agir humano}

Seres humanos fazem coisas, cantam, choram, dançam, lutam, pedem, riem, trabalham, admiram, etc. Esses verbos e tantos outros caracterizam aquelas atividades que chamamos de ações/agir. Somos sempre relacionados a coisas (mundo) ou a outras pessoas - é impossível não ser relacional. O mundo parece algo não neutro, mas é um mundo para algo, seja para trabalhar, rir, dançar, etc. São essas relações-para que Tamboer (1994) chama de relações de significação/significativas. Fazemos algo em relação ao mundo, e esse algo tem a ver com significações e sentidos para nós mesmos. Assim, uma pequena bola para um bebê tem o significado de morder. Depois de morder (como a bola não é mais a mesma), o significado se modifica, passando a ser de não mais mordê-la. E essa relação de uma criança com a bola pode seguir se modificando - pode rolar, pode quicar, e assim por diante -, pois o que não muda é o fato de sempre existirem relações significativas. Agir/ações são, nesse sentido, uma realização de relações significativas.

Logo, podemos nos perguntar, o que é o específico nessas ações/agir de movimentos? O que há de diferente entre o (fazer) rolar uma bola e o (fazer) morder uma bola para um bebê? Para poder caracterizar uma ação (agir) como um agir de movimento, é necessário, conforme Tamboer (1994), levar em consideração três pré-condições inter-relacionadas:

1. Pela relacionalidade ao mundo, a intencionalidade deve estar também em primeiro lugar orientada/dirigida a uma "mudança de lugar" (por exemplo, no saltar);

2. O contorno deve ser caracterizado, com conceitos relevantes na hora do mudar de lugar (por exemplo, saltar sobre algo);

3. O modo como acontecem as mudanças de lugar deve ser caracterizado em forma de conceitos quanto às relações espaço-temporais (por exemplo, rápido, lento, alto, longe).

A partir de uma imagem de corpo relacional, assim se compreende um agir, como uma forma do "compreender-o-mundo-em-ação". E nesse agir, o ser humano e o mundo não podem ser definidos independentemente um do outro. Agir aqui significa um "atualizar" o constante acordo/confirmação da intencionalidade humana com o mundo intencionado. Isso caracteriza/marca que, em um agir por movimentos, esse acordo/confirmação foi feito, inicialmente, em uma situação de mudança da localização.

A partir da compreensão inicial do "Se-Movimentar" - incluindo as posições de Tamboer e sua "Rede complexa de relações significativas" para o "Se-movimentar" humano (1994) - é possível deduzir que o "Se-movimentar humano", na concepção de movimento relacional, deve passar pelos seguintes esclarecimentos: a) Ele (se-movimentar) se realiza mediante um contexto específico, e que, por isso, sua interpretação deve sempre levar em consideração as influências desse contexto; b) É visto como uma forma de mudança 
de localização, que pode ser caracterizada com auxílio de verbos e substantivos evidentemente relacionados ("Se-movimentar" é um agir humano); c) Pessoal - não é assim que a totalidade estará perfilada e facilmente disponível, e sim, de como o sujeito individual interpreta e avalia os fatores fundantes do movimento e, uma vez se movimentando, constitui a sua formação (forma), resultando disso um todo pleno de sentidos; d) "a abertura de uma possibilidade ótima para um diálogo motor com o mundo, onde o aluno pode reconhecer suas possibilidades e limites para que ele se 'torne ele próprio' e com isso também aprenda a experimentar, pelo diálogo de perguntar e responder a seu mundo, o seu próprio campo existencial" (KUNZ, 2007, p. 11).

Trata-se do fato de que as crianças, por meio de situações de ensino de movimento, possam se sentir mais familiarizadas e cada vez mais confiantes, conhecendo melhor sua corporeidade e assim podendo explorar um campo existencial cada vez maior. O ensinar movimentos deve levar as crianças a descobrir que conseguem explorar melhor um lugar no mundo. Com essa concepção de ensino, pretende-se superar o ensino de gestos motores padronizados. As crianças que aprendem a se familiarizar com as mais diferentes e variadas situações de movimento, certamente não se interessam em ficar um dia inteiro na frente da televisão ou computador. Isso abre perspectivas múltiplas que vão desde o saber argumentar quando se faz necessário até explorar as mais variadas situações e ambientes, abrindo e estendendo seu campo existencial. Ou então, "abrir as chances para uma autodeterminação, autoconfirmação e confirmação de seu mundo para um constante estar se desenvolvendo, aventurando, pelo prazer de um 'ser-aí-juntos'" (HEIJ, 2009, p. 58).

Como o movimento (se-movimentar) aqui é entendido como uma forma de conduta, as crianças não precisam estar em plena forma (preparados por uma academia ou por algum treinamento especial), mas ter condições de, em conjunto com as demais, realizar coisas como, por exemplo, descobrir e adaptar regras de brincar e jogar e o arranjo de situações de movimentos adequados. Com isso, elas devem aprender também a conhecer suas possibilidades individuais a serviço do outro ou de um objetivo ou proposta comum a todos.

Para Gordijn (1980 apud HEIJ, 2009), não se trata de decifrar o "Ser" do Ser Humano, mas sim, as relações de sentido com o outro e as coisas, que foram justamente trabalhadas pelo autor com relação ao "Se-movimentar", especialmente nas questões envolvendo o ensino da Educação Física.

Vale lembrar que o conceito de desenvolvimento individual que aqui seguimos deve ser entendido como um conceito relacional e do qual a teoria de Gordijn muito se aproveitou. Ele próprio (1980 apud HEIJ, 2009, p. 18) afirma: "Ser adulto é uma espécie de variabilidade, nunca é uma estação final de uma viagem para o desenvolvimento". E nesse caminho ou viagem, também não é possível encontrar diferentes fases que deveriam levar todos ao "estado final de ser adulto". E como também não existem limites para esse caminho, preferimos usar o conceito de desenvolvimento individual em lugar de desenvolvimento para a fase adulta. Mais adiante, acrescenta: "ser possível por isso se dizer que cada ser humano nasce fortemente relacionado a seu vínculo original com o mundo, e por isso desenvolve a sua individualidade". 
O desenvolvimento para a individualidade é um desenvolvimento para uma autoconsciência no contexto de uma existência. Mas também é, ao mesmo tempo, o desenvolvimento de mundo dos seres humanos, que se torna um mundo para cada um, onde cada um se desenvolve e produz sua própria forma existencial para o mundo.

$\mathrm{O}$ autor ainda tece algumas considerações sobre as diferenças entre a concepção de desenvolvimento humano que defende e de outros autores como, por exemplo, Gordijn (1980) e outros que se apoiam mais nos resultados de um desenvolvimento forjado por meio de treinamentos e condicionamentos (os resultados são aplicados aos fatores de desenvolvimento), do que em um processo natural. Nesse caso, se trata antes de tipos de comportamento (Behavior), os quais, de fato, não contribuem para se compreender melhor a complexidade do desenvolvimento humano. Já a questão da compreensão do desenvolvimento a partir de resultados esperados ou não, trata-se, na verdade, de Condutas (ações), cujos resultados de aprendizagem devem se transformar em resultados que possam favorecer o desdobramento de um ser em pleno desenvolvimento, como uma criança, por exemplo. No caso do ensino em Educação Física, o desenvolvimento da individualidade se realiza pelas diferentes formas das experiências com relações de sentido.

Então, nada melhor que nos reportarmos a Gordijn (1980 apud HEIJ, 2009), que sempre acentuava o fato de que o ensino do movimento humano, neste caso, da Educação Física, deve se dedicar ao máximo para que todas as crianças possam ter e conquistar chances e direitos iguais. $\mathrm{O}$ autor pretende, com isso, fazer justiça à singularidade da criança. Trata-se, para ele, de respeitar e honrar as diferenças. Essa proposta é muito conhecida na pedagogia do pensamento pela diferença de Gordijn. Ele empresta às crianças sua voz, especialmente àquelas que, muitas vezes, precisam se submeter arduamente aos regimes das escolas e dos adultos em geral. Portanto, busca esclarecer essas diferenças e mostrar possibilidades superadoras para elas, no sentido das orientações previamente estabelecidas (objetivos centrais e finais, provas finais, testes, etc.).

\section{Brincar como possibilidade fundamental do Se-Movimentar da Criança}

A criança com saúde sente um enorme prazer em "Se-Movimentar". A base desse movimento reside na necessidade natural da criança de brincar. Mesmo "correndo à toa", ela está brincando. Consideramos esse ato natural porque o ser humano nasce para ser livre e criativo. E o sentido dessa liberdade e criatividade é expresso na brincadeira: liberdade por poder e querer decidir suas realizações e criatividade pela possibilidade de constituir sentidos e significados àquilo que realiza.

Para algumas crianças, o simples fato de poder brincar em um espaço seguro, permissível, acolhedor e conforme ao que querem escolher, da forma como querem escolher, já é suficiente para promover as reconfigurações necessárias ao bem-estar e ao resgate de um funcionamento saudável em sua interação com o mundo (AGUIAR, 2005).

A tendência natural de "Se-Movimentar" e brincar da criança rapidamente se transforma em atividade social e cultural pela própria apropriação de elementos da 
cultura, e também, pela indução do meio onde nasce, originada, na maioria das vezes, pela imposição dos adultos a atividades aceitas e reconhecidas por eles. Assim, por exemplo, destacam-se nitidamente duas formas do brincar na criança: o "brincar espontâneo" e o "brincar didático". Infelizmente, a maior parte da literatura se refere apenas a esse último, fornecendo elementos de interpretação e aplicação prática.

Todo ser humano tem uma inerente necessidade de "Se-movimentar". A criança sabe disso e busca incessantemente atender a essa necessidade básica, realizando-a no ato de brincar. O brincar é o ato mais espontâneo, livre e criativo, e por isso, para uma criança, significa uma realização plena para o desenvolvimento de seu ser. Logo, deveria ser entendido pelos adultos como algo sagrado para a criança. Impedir essa possibilidade é, segundo Costa (2011), uma "Lebensentzug" (com base em ZurLippe, 1987), isto é, uma extração de vida sem morrer.

Em boa parte da literatura da área de Educação Física com crianças, e que se refere ao seu brincar, existe uma espécie de "brincar didático", sob diferentes nomeações: aprendizagem motora, psicomotricidade, motricidade infantil, jogo, etc. E até mesmo na literatura específica que aborda a temática do brincar e do brinquedo infantil existe esse olhar "didático".

Enfim, a "didática do brincar" se ocupa mais do conteúdo e da utilização da brincadeira do que, propriamente, da criança que brinca. Isso ocorre nas teorias do Movimento Humano na Educação Física, nas quais o privilégio de estudo se concentra antes nas possibilidades de cópia e imitação de movimentos já criados, do que na criança, no ser humano que "se-movimenta".

Muita literatura sobre o tema em questão também apresenta um enorme interesse em classificar o brincar da criança. Assim se destacam, em primeiro lugar, as grandes classificações, com afirmações de que o brincar é cultural para alguns, social para outros, ou ainda, psicológico para um grande grupo de pesquisadores. Somente aqueles que pesquisam e convivem com crianças descobrem que o brincar é individual, cultural, universal, social, natural, corporal, emocional, enfim, total.

Por causa dessas classificações acerca das formas de brincar é que, cada vez mais, alguns teóricos são levados a considerar que a criança, quando brinca, está se preparando para o futuro. São típicas as classificações dessa natureza: por exemplo, as brincadeiras de imitação que a criança realiza, quando imita, por exemplo, profissões adultas, como médico, enfermeira, bombeiros, caminhoneiros, etc. As brincadeiras se desenvolvem pelo fato de as crianças causarem emoção nas relações que estabelecem com o mundo, com os outros e consigo mesmas. Por isso, é sempre uma atuação do presente, sem perspectivas para o futuro e sem intenções, salvo o prazer de brincar. Não são, pura e simplesmente, as atividades motoras, ou então, suas formas e intensidades de realização, importantes na brincadeira da criança, mas sim, sua vivência subjetiva.

Desta forma, torna-se muito complexa uma interpretação do brincar da criança, tendo em vista outro fator complexo, que é a percepção dessa atividade/atitude e o envolvimento total da criança, destituído do olhar e análise do adulto. A criança se expressa 
brincando, seja para o mundo, para os outros ou para si mesma. Portanto, não é tão importante se ela, ao brincar, imita, simboliza ou inventa coisas. O que importa é o que ela está dizendo, expressando com seu brincar, pois, ao expressar, ela dá sentido ao que faz. Logo, é um erro estudar o brincar da criança mediante uma perspectiva da realidade do adulto, e pior ainda, mediante uma interpretação conforme a aprendizagem e/ou seu desenvolvimento psicomotor, ou então, outra dimensão humana.

Com as condições do mundo tecnologizado e com a falta de espaços, a criança consegue se introduzir com grande facilidade no mundo eletrônico, e há quem veja nessa apropriação infantil uma enorme chance à evolução da aprendizagem da criança para o mundo do adulto. Consideram isso, na classificação do brincar, uma atividade simbólica na qual se desenvolve um tipo de percepção, abstração e internalização das relações, especialmente cognitivas, e que pode influenciar o relacionamento da criança com o mundo, com o outro e consigo mesma. Sabemos que essas atividades eletrônicas pouco atendem à necessidade inerente que a criança sente para "Se-movimentar", assim como resulta evidente que é através dessa totalidade do envolvimento corporal, desse "Se-movimentar", que ela poderá tomar consciência de si e do mundo. Essa consciência, por sua vez, desenvolve um senso de eu que promove a criatividade autônoma. Esse é o tipo de "sobrevivência" (OAKLANDER, 2009) que a criança procura desesperadamente e que requer o auxílio do adulto. E isso não tem nada a ver com a aprendizagem para a vida futura, pois:

O brincar não tem nada a ver com o futuro. Brincar não é uma preparação para nada, é fazer o que se faz em total aceitação, sem considerações que neguem sua legitimidade. Nós adultos, em geral, não brincamos, e frequentemente não o fazemos quando afirmamos que brincamos com nossos filhos. Para aprender a brincar, devemos entrar numa situação na qual não podemos senão atentar para o presente. (MATURANA; VERDEN-ZOLLER, 2004, p. 234)

A grande atenção dada ao brincar da criança como preparação para a vida futura também leva pesquisadores e autores do tema a considerar e valorizar a competição na brincadeira, já que esta é uma característica marcante de nosso modelo social. Aprovam, dessa forma, modelos de brinquedo que fomentam a competição e a violência. Assim, Brougére (1997, p. 79), um dos clássicos do assunto sobre crianças e brinquedos, ao analisar a dificuldade que certas crianças têm de expressar sua agressividade em um mundo de total controle, afirma que "a brincadeira de guerra permite exprimir esta agressividade de modo legítimo e, sobretudo, aceitável pelo seu meio". Isso é o mesmo que afirmar que crianças podem e até devem brincar com armas de brinquedo, pois assim conseguem, da melhor forma, se ajustar ao mundo onde vivem, expressando sua agressividade. Isso só pode ser mais um sinal de que ainda não sabemos o verdadeiro sentido do brincar da criança. Ela vive do brincar e, para brincar, não há maldade, tampouco expressão de agressividade.

A criança precisa se encontrar na brincadeira, com outras crianças ou mesmo sozinha, como uma participante ativa, com força e prazer de decidir, de mudar, enfim, de inventar e criar. O brincar, em suma, é para ela um "Se-Movimentar criativo". 


\section{O brincar criativo}

A necessidade de uma teoria para o Movimento Humano que supere o tradicional conceito de deslocamento no tempo e espaço de um corpo ou partes deste, e que tenha no centro de interesse o sujeito ou a criança que se-movimenta, já foi diversas vezes abordada e tratada por Kunz (1991; 1994; 2001) e Trebels (1992). Dois momentos dessa teoria são importantes para se destacar novamente. Primeiro, é o fato de que, na concepção de movimento dessa teoria, a criança que se-movimenta não é uma mera apresentadora de movimentos criados e apresentados pelos adultos, mas autora, constituidora de sentidos e significados em seu "Se-Movimentar". Por isso, sempre há uma intencionalidade criativa no ato de se-movimentar. Para ser criativo em seu "Se-Movimentar", a criança não precisa inventar coisas novas no seu brincar, mas, justamente, constituir sentidos frente ao que realiza. Já o segundo momento, o "Se-Movimentar", passa a ser uma vivência na qual o espaço não é o espaço físico, material, mas o espaço vital; assim também o tempo não é o tempo do relógio, mas o tempo vital. São as vivências subjetivas e sua expressão prazerosa que importam, como no brincar antes descrito, por isso, a relação dessas duas categorias.

Ser criativo é uma capacidade de dar existência a algo, ou então, de estabelecer relações ainda não concebidas, inventar ou descobrir algo novo ainda não conhecido. E esse novo pode também se referir a um novo significado, um novo valor dado a algo já conhecido.

Assim, por exemplo, a criança que todo dia aprende algo novo por seus próprios meios e condições está, de certa forma, criando, construindo seu mundo. Ou então, a partir de contextos e situações antigas já conhecidas, podem-se criar novas significações e novos valores. Isso é muito frequente no brincar da criança com liberdade. $\mathrm{E}$, quanto mais cedo o adulto interferir nessa "criação" por excelência, menos criativo e independente essa criança será quando crescer. Em um sentido mais geral, sobretudo às crianças, todas suas atividades têm certo significado criativo, sendo que elas necessitam disso; é o processo de tornar-se humano pela própria natureza, antes da intervenção sociocultural.

Eis a importância que ocupa a brincadeira e o jogo na vida do ser humano em crescimento e desenvolvimento. Afinal, essas atividades, quando realizadas de forma livre e espontânea, se concretizam sempre em relações criativas. E no futuro, esse mesmo entendimento e essas mesmas relações criativas podem se estender para a Arte ou para as Ciências. No entanto, percebemos que o tema da criatividade como conteúdo humano de maior transcendência, quando gerado a partir da percepção, sensibilidade e intuição humana, constitui um assunto ainda pouco estudado (KUNZ, 2009).

Logo, o afã criativo, que naturalmente todos temos, nasce de uma sensibilidade intuitiva desperta. Pela criatividade, nos sentimos como se fôssemos lançados para fora de um contexto rotineiro e conhecido, ou de experiências passadas, e para que isso aconteça, precisamos nos sentir livres e abertos para novas experiências e contextos. Parte dos problemas humanos, deduz-se, nasce da falta de "vazão" aos impulsos criativos, pois o racional, o lógico funcional de nossa forma de pensar, tem um "efeito desumanizador" e banaliza o humano, uma vez que desrespeita a inteligência intuitiva, presente na 
infância quando se brinca ou desenha. A inteligência intuitiva, que leva à criação, tem a sua origem na imaginação e na fantasia. Portanto, surge nos momentos em que a pessoa está completamente passiva ou quando as condições do meio permitem um livre e espontâneo expressar, como nas brincadeiras e jogos, em geral.

Já entendemos que a criança, quando participa da descoberta de mundo, dos outros e de si própria de forma livre, age de modo extremamente criativo. O objeto com que brinca ou o desenho que realiza podem ser idênticos aos que outras crianças brincam ou desenham, embora para ela tenha um sentido novo. O problema começa quando os adultos classificam, avaliando as ações da criança. É ela que dá forma e significado a algo que antes não existia, até o momento em que a escola, a família e as demais instituições formadoras the apresentarem o que "deve" ou "não deve" conhecer, o que "pode" ou "não pode" fazer e o que "é" ou "não é" importante na vida. Esvazia-se, assim, todo o impulso criativo, toda a inteligência intuitiva, toda a sensibilidade transcendental e toda a percepção individual e única de mundo e das coisas desse mundo. Para Kunz (2009), a identidade individual dá lugar à identidade social, ou seja, o ser "como ninguém é" se reduz em um ser "como todo mundo é". Seria possível recuperar alguma coisa? Sim. Em um momento de grande desafio, o ser humano adulto recupera um pouco de sua intuição e criatividade. As atividades prazerosas da brincadeira infantil poderiam servir como certo desafio para despertar essas qualidades.

A importância dos processos criativos no ser humano é bastante conhecida na música, nas artes e nas terapias da psicanálise. Por exemplo, Violet Oaklander (1980), da psicanálise Gestáltica, utiliza os jogos dramáticos criativos para resolver problemas e traumas na infância, fazendo com que as crianças tenham uma melhor autoconsciência. Corpo, imaginação e sentidos se tornam mais conscientes nas brincadeiras criativas, e assim, desenvolve-se um sentido de eu mais forte e decisivo. Outros autores, da mesma linha de pensamento, também acreditam que, com as brincadeiras, a criança consiga se desdobrar melhor e tornar-se ainda mais ela mesma.

Para Kunz (2009), o que torna um ser humano criativo é certamente sua capacidade de diálogo com o mundo, os outros e consigo mesmo. A forma como esse diálogo começa na infância, como sabemos, parte de seu "Brincar e Se-movimentar". A criança se expressa pelo movimento, enquanto o movimento possibilita que ela questione a realidade da vida. E é assim, dando liberdade a essa importante expressividade e diálogo, que ela se forma como ser autônomo e criativo.

A criança que brinca está sempre presente nessa atividade. Nas atividades que realiza, ela consegue recuperar sentidos e significados, se encontrar e se perder ao mesmo tempo e, acima de tudo, esquecer o mundo, o tempo e a vida como compromisso. A realização de atividades de movimentos, esportes e jogos, mesmo como tema de aprendizagem na escola, deveria alcançar essas dimensões nas crianças e jovens. Afinal, dessa forma, haveria um "Se-movimentar" livre que se encaminharia para a imaginação e a fantasia, pelo abandono do mundo ao redor, deixando ela se levar pela aventura de estar plenamente concentrada em uma atividade desafiadora e socialmente referenciada e articulada. A realidade, assim, se transforma, e a vida ganha sentidos que promovem 
sentimentos de autorrealização, prazer e conhecimentos que transcendem o objetivamente realizado e coletivamente vivenciado.

Logo, quando não se permitir mais às crianças, pelo processo de ensino a que são submetidas (até mesmo nas creches), experiências próprias de movimento, brincadeiras e jogos a favor de um movimento "correto", pré-dado e criado por terceiros, para atender a compromissos futuros de desenvolvimento, isso dará margem a uma das experiências mais alienantes e castradoras da liberdade e criatividade humana. Diante da falta de atividades que negam considerar sentidos e valores subjetivamente significativos, promove-se uma verdadeira "extração de vida" dessas crianças em seu processo de "se-movimentar". Afinal, a vida que pulsa em um corpo jovem está em constante busca por vivências e experiências subjetivamente significativas, o que significa dizer criação.

As brincadeiras ocupam um lugar central na vida das crianças, sendo que não fazem distinção entre brincar e fazer coisas sérias; sendo assim, "brincar é o que fazem de mais sério" (SARMENTO, 2004, p. 15).

É lamentável conhecermos tão pouco do ser humano que "se-movimenta", e darmos, por outro lado, tanta importância ao movimento que o ser humano, para contextos prédefinidos, realiza, isto é, que é capaz de copiar e imitar. É por isso que, normalmente, profissionais da Educação Física que trabalham com educação infantil ficam sem saber o que fazer. As condições, não apenas fisiológicas das crianças, mas o seu ser assim para o mundo, não permitem que sejam dependentes de cópia e imitações. Embora tentativas estejam sendo realizadas, e não apenas nas atividades que envolvem o movimento humano, a escolarização precoce atualmente conduz exatamente a isso, ou seja, à "extração de vida" da infância - vida que seria naturalmente encaminhada à fantasia, à imaginação e à criatividade, com o pleno desenvolvimento dos seis sentidos (incluindo a intuição que a criança ainda tem) e de infinitas potencialidades.

\section{CONSIDERAÇÕES FINAIS}

A reflexão aqui apresentada faz parte de uma série de pesquisas sobre a mesma temática e vem sendo desenvolvida há um bom tempo. Assim sendo, a preocupação inicial é com a criança, seu desenvolvimento e inserção precoce no mundo da escola e do ensino e, principalmente, de uma ausência cada vez maior em suas vidas daquilo que decidimos conceituar como "Brincar e Se-movimentar".

De certo modo, ficamos espantados com o problema e com as muitas pesquisas apresentadas nas áreas da saúde, especialmente, em medicina e psicologia, e também na educação, e surpresos com a falta de produção na área que consideramos como a mais destacada autoridade sobre o tema, a Educação Física, propriamente.

Na construção deste ensaio, foi significativo para nós o fato de compreender que, para se entender as crianças, é preciso entender muito do outro, do mundo e também de nós mesmos. Para isso, não basta apenas olhar com os olhos, mas sentir com todos os sentidos; é preciso sonhar, imaginar, fantasiar com elas, usar muito de nossa própria intuição. 
Para Kunz (2009), das mil linguagens, caminhos e possibilidades que a criança encontra em seu despertar para o mundo, a Escola lhe subtrai novecentos e noventa e nove. E, se assim mesmo ela consegue se ajustar, reprimir impulsos internos, aceitar as regras do jogo social e se adaptar às exigências do entorno, ela, ainda assim, pode surpreender e se tornar um profissional, um atleta ou artista altamente qualificado. Porém, a "Vida que Ihe foi Extraída" começa a se revelar em múltiplas fraquezas, que modernamente são denominadas doenças psíquicas. A psicanálise começa a se congestionar de pessoas cada vez mais jovens.

Muito desses comportamentos seriam amenizados se os adultos, educadores, administradores e demais envolvidos no processo de desenvolvimento compreendessem melhor o valor das experiências e da participação infantil. Talvez seja por isso que Theodor Adorno (2003), em seu livro Educação e Emancipação, disse que, se queremos salvar o mundo, temos que dar mais atenção à primeira infância.

Desta forma, concluímos que há muito ainda a se pesquisar sobre esse assunto, especialmente sobre a questão do que é Ser Criança, para poder descobrir melhor e também justificar melhor o que nós denominamos "inerente necessidade vital da criança, seu brincar e se-movimentar". Com isso, a Educação Física também poderá abrir e ampliar um valoroso e vasto campo de ensino e pesquisa, podendo, no futuro, ser uma das áreas mais importantes e valorizadas da Educação porque ensina às crianças, ou seja, ao ser humano desde sua tenra idade, "a arte do saber viver melhor".

\section{REFERÊNCIAS}

ADORNO, T. W. Educação após Auschwitz. In: Educação e Emancipação. $3^{\text {a }}$ ed. São Paulo: Paz e Terra. 2003.

AGUIAR, L. Gestalt-terapia com crianças: teoria e prática. São Paulo: Livro Pleno, 2005. BROUGÈRE, G. Brinquedo e Cultura. 2a ed. São Paulo: Cortez, 1997.

COSTA, A. R. CRIANÇAS, o que elas querem e precisam do mundo, do adulto e delas mesmas? Dissertação de Mestrado. Apresentada ao Programa de Pós-Graduação em Educação Física da UFSC, Florianópolis, 2011.

HEIJ, P. Grondslagen van, verantwoordbewegingsonderwijs - Filosofischeem pedagogischedoordenking van relationeelgefundeerdbewegingsonderwijs. Budel: Damon, 2006. (Tradução para o alemão de Andreas H. Trebels; tradução para o português de Elenor Kunz)

KUNZ, E. Percepção, sensibilidade e intuição para as possibilidades criativas no esporte. In: STIGGER, M. P.; LOVISOLO, H. (Orgs.). Esporte de Rendimento e Esporte na Escola. Campinas: Autores Associados, 2009.

KUNZ, E. "Brincar e Se-Movimentar": tempos e espaços na vida da criança. Ijuí: UNIJUÍ, 2015.

MATURANA, Humberto. Amar e Brincar: fundamentos esquecidos do humano do patriarcado à democracia. São Paulo: Palas Athenas, 2004. 
OAKLANDER, Violet. Descobrindo Crianças, a abordagem gestáltica com crianças e adolescentes. São Paulo: Summus Editorial, 1980.

OAKLANDER, Violet. VerborgeneSchätzeheben: Wege in die innere Welt Von Kindern und Jugendlichen. Stuttgart: Konzepte der Humanwissenschaften, 2009.

SARMENTO, M. J. As Culturas da Infância nas Encruzilhadas da 2. ${ }^{a}$ Modernidade. In. SARMENTO, M. J.; CERISARA, A. B. (Orgs.). Crianças e Miúdos. Perspectivas Sociopedagógicas da Infância. Porto: ASA, 2004.

TAMBOER, J. W. J. Philosophie der Bewegungswissenschaften. Hannover: Afra, 1994. (Tradução livre feita por Elenor Kunz)

TONUCCI, F. Quando as crianças dizem: Agora chega! Porto Alegre: Artmed, 2005.

TREBELS, A. H. Spielen und Bewegen na Gäreten. Hamburg: Rororo, 1983.

ZUR LIPPE, S. SinnenbewuBtsein: GrundlegungeineranthropologischenÄstheitik. Hamburg: Rowohltsenzyklopädie, 1987.

Recebido em: Setembro/2016

Aprovado em: Fevereiro/2017 